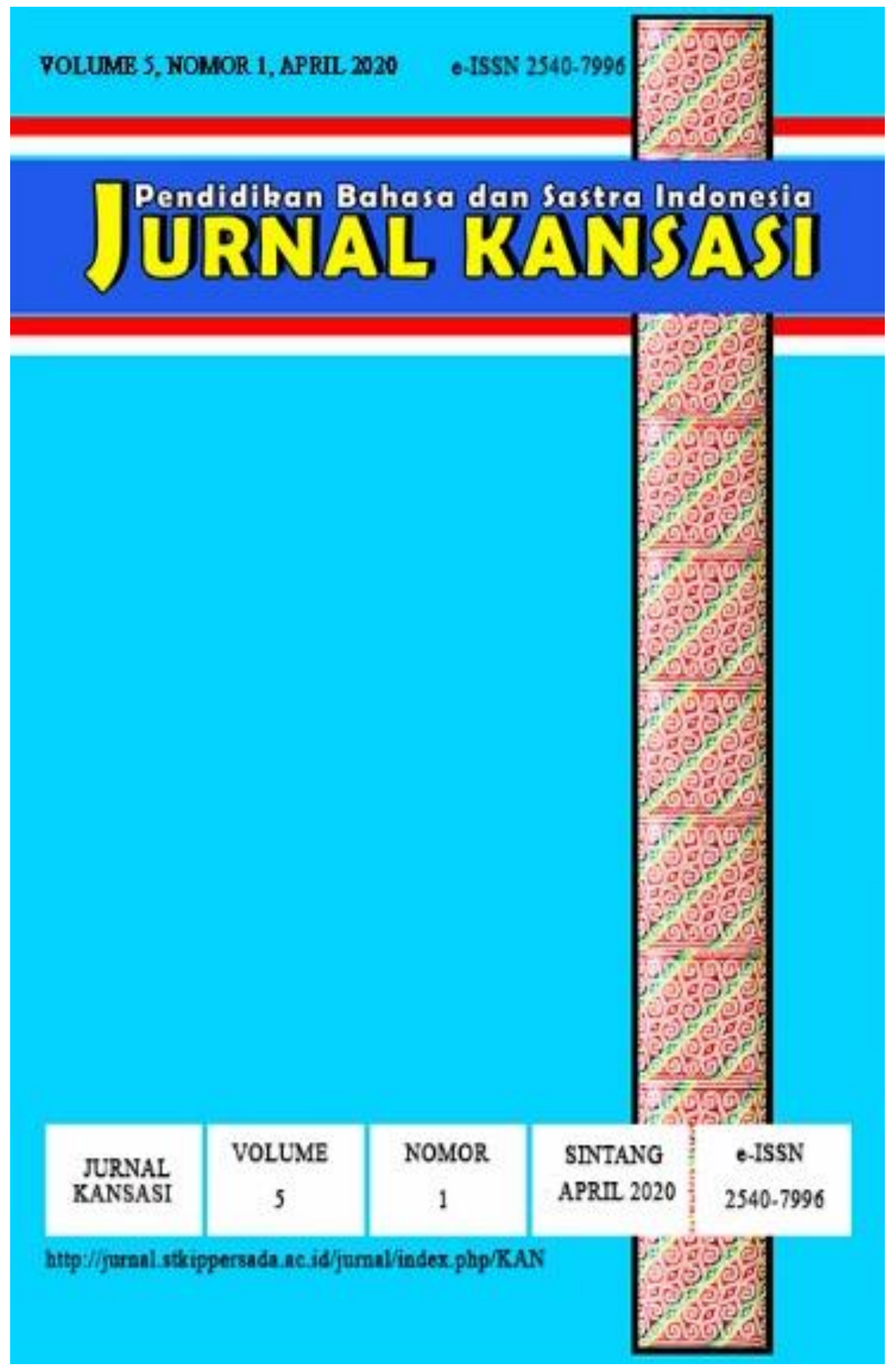




\section{JURNAL KANSASI \\ Volume 5, Nomor 1, April 2020}

Jurnal online pendidikan bahasa dan sastra Indonesia terbit dua kali setahun yaitu pada bulan April dan Oktober. Berisi tulisan yang diangkat dari hasil telaah dan penelitian di bidang pendidikan, bahasa, dan sastra Indonesia.

\section{Editor In Chief}

Debora Korining Tyas

\section{Deputy Chief Editor}

Sri Astuti

\section{Editor}

Tedi Suryadi

Ursula Dwi Oktaviani

Yudita Susanti

Muhammad Thamimi

Muchammad Djarot

\section{Reviewer}

Yusuf Olang

Herpanus

Bani Sudardi

Yoseph Yapi Taum

Agus Wartiningsih

\section{Administratative Staffs \\ Valentinus Ola Beding \\ Evi Fitrianingrum}

Alamat Redkasi: Program Studi Pendidikan Bahasa dan Sastra Indonesia STKIP Persada Khatulistiwa Sintang, Jl. Pertamina Sengkuang, Kotak Pos 126, Hp/WA. 082150544710.

Website e-journal KANSASI: http://jurnal.stkippersada.ac.id/jurnal/index.php/KAN

Jurnal ilmiah online KASASI diterbitkan oleh Program Studi Pendidikan Bahasa dan Sastra Indonesia STKIP Persada Khatulistiwa Sintang. Terbit sejak April 2016.

Penyunting menerima tulisan ilmiah yang belum pernah diterbitkan dimedia lain, baik cetak maupun elektronik. Naskah diketik untuk ukuran HVS A4 dengan spasi satu koma lima, maksimal 20 halaman. Tulisan yang masuk direview dan selanjutnya untuk diterbitkan. 


\section{JURNAL KANSASI \\ Volume 5, Nomor 1, April 2020}

\section{DAFTAR ISI}

Halaman

Hubungan Kemandirian Belajar Terhadap Hasil Belajar Siswa pada Mata Pelajaran Bahasa Indonesia Kelas VIII $1-8$

SMP N 02 Tempunak

\section{Herpanus, Evi Fitria Ningrum, Ahensius Bantut}

STKIP Persada Khatulistiwa Sintang

Analisis Kesulitan Membaca Permulaan pada Sub Tema Tugasku

Sebagai Umat Beragama pada Siswa Kelas II SD Negeri 06

Setapang Laut Ketungau Hilir

Ursula Dwi Oktaviani, Gabriel Serani, Etikustini

STKIP Persada Khatulistiwa Sintang

Analisis Struktural Kumpulan Cerita Rakyat

Dayak Jangkang Tanjung

Valentinus Ola Beding, Tedi Suaryadi, Frideta Heni

STKIP Persada Khatulistiwa Sintang

Peningkatan Keterampilan Menulis Karangan Deskripsi

Menggunakan Media Miniatur (Maket)

Debora Korining Tyas, Sudarto, Ahmad Ridho Inoviar

STKIP Persada Khatulistiwa Sintang

Hubungan Kebiasaan Menulis dengan Kemampuan Menulis Cerpen pada Siswa Kelas XI Sekolah Menengah Atas

Nusantara Indah Sintang

Yusuf Olang, Evi Fitrianingrum, Markulanus Alex

$55-63$

STKIP Persada Khatulistiwa Sintang

Peningkatan Hasil Belajar Siswa Menggunakan

Metode Talking Stick pada Pembelajaran Tematik

Tedi Suryadi, Meranti Sintauli Tampubolon

$64-70$

STKIP Persada Khatulistiwa Sintang

Peningkatan Penguasaan Kosakata Bahasa Indonesia

Menggunakan Media Gambar pada Siswa Kelas 1

Sekolah Dasar Negeri 43 Tapang Aceh Tahun Ajaran 2019/2020

$71-80$

Gabriel Serani, Ilinawati, Lidia Heni

STKIP Persada Khatulistiwa Sintang 
Hubungan Hasil Belajar Siswa Dengan Kemampuan

Menerapkan Nilai-Nilai Pancasila

Agnesia Hartini, Lukas Robinson

$81-91$

STKIP Persada Khatulistiwa Sintang

Proses Dan Makna Simbol Ritual Munjong Dayak Tobag

Yudita Susanti, Yusuf Olang, Marselina Risca

$92-98$

STKIP Persada Khatulistiwa Sintang

Penerapan Pendekatan Eksploratory Discovery untuk Meningkatkan

Motivasi dan Hasil Belajar Kognitif

Sirilus Sirhi, Hendrikus Julung, Valentina Suci Susanti

$99-112$

STKIP Persada Khatulistiwa Sintang

Analisis Makna Bahasa Promosi Katalog Oriflame

Edisi Bulan Januari-Maret Tahun 2019

$113-126$

Ursula Dwi Oktaviani, Debora Korining Tyas, Ira Winarti

STKIP Persada Khatulistiwa Sintang

Peran Guru Pkn dalam Membina Civic Skill Siswa

Sekolah Menengah Pertama Negeri 7

Agnesia Hartini, Simon Petrus

$127-137$

STKIP Persada Khatulistiwa Sintang 
Vol. 5, No. 1, April 2020

e-ISSN: 2540-7996

http://jurnal.stkippersada.ac.id/jurnal/index.php/KAN/index

\title{
ANALISIS STRUKTURAL KUMPULAN CERITA RAKYAT DAYAK JANGKANG TANJUNG
}

\author{
Valentinus Ola Beding ${ }^{1}$, Tedi Suryadi ${ }^{2}$, Frideta Heni $^{3}$, \\ ${ }^{1}$ STKIP Persada Khatulistiwa, ${ }^{2}$ STKIP Persada Khatulistiwa, \\ ${ }^{3}$ STKIP Persada Khatulistiwa,
}
e-mail: fvalentinus.beding86@gmail.com ${ }^{1}$,tedisuryadi.198724@gmail.com², fridetaheni8899@gmail.com ${ }^{3}$

Diajukan, 4 Februari 2020, Diterima, 4 Maret 2020, Dterbitkan, 1 April 2020

\begin{abstract}
ABSTRAK
Penelitian ini bertujuan untuk mendeskripsikan hasil analisis terhadap unsur intrinsik dan nilai moral dalam kumpulan cerita rakyak Dayak Jangkang Tanjung. Metode dalam penelitian ini adalah metode Kualitatif berbentuk Deskriptif. Peneliti menggunakan teknik observasi, teknik perekaman. Alat pengumpulan data yang digunakan adalah lembar observasi, handpone android, kamera handpone. Berdasarkan hasil analisis ditemukan unsur intrinsik kumpulan cerita rakyat Dayak Jangkang Tanjung Dusun Kompor Baru Desa Engkode Kecamatan Mukok Kabupaten Sanggau memiliki 5 tema, terdapat alur cerita dengan jenis alur maju dan alur campuran, 8 latar waktu, 18 latar tempat, 5 latar sosial, terdapat 30 penokohan dan perwatakan, sudut pandang dengan jenis campuran, gaya bahasa majas metafora, majas interupsi, dan bahasa yang biasa, serta terdapat 5 amanat. dalam kumpulan cerita rakyat juga terdapat nilai moral berkaitan manusia dengan Tuhan, hubungan antara manusia sesama manusia dan hubungan antara manusia dengan alam. Dari analisis struktural kumpulan cerita rakyat yang telah dikaji, ditemukan banyak hal positif yang dapat diterapkan di kehidupan dan penelitian ini diharapkan kepada pembaca atau peminat untuk menjaga kebudayaan secara turun-temurun khususnya kebudayaan. Peneliti yang akan melakukan penelitian lebih lanjut agar memahami unsur struktural dalam kumpulan cerita rakyat Dayak Jangkang Tanjung Dusun Kompor Baru Desa Engkode Kecamatan Mukok Kabupaten Sanggau.
\end{abstract}

Kata kunci: analisis struktural, unsur intrinsik, nilai moral, cerita rakyat

\section{ABSTRACT}

This study aims to describe the results of the analysis of the intrinsic elements and moral values in the collection of Dayak Jangkang Tanjung folklore collection. The method in this research is descriptive qualitative method. Researchers use observation techniques, recording techniques. Data collection tools used were observation sheets, android mobile phones, cellphone cameras. Based on the results of the analysis, it found that intrinsic elements of Dayak Jangkang Tanjung Dusun Kompor Baru Desa Engkode Village Kecamatan Mukok Sanggau Regency have five themes. It has storylines which are forward plot and mixed plot, eight-time setting, eighteen background, five social backcground, thirthy characterization, and characters. Point of view with diverse types, metaphorical style of speech, interruption, and ordinary language, and there are five mandates. In a collection of folklore, there are also moral values related to humans and God, the relationship between humans and humans, and the relationship between humans with nature. From the results of the structural analysis of the folklore collection that has studied, it found that many positive things can implement in life. 
Vol. 5, No. 1, April 2020

e-ISSN: 2540-7996

http://jurnal.stkippersada.ac.id/jurnal/index.php/KAN/index

And this research is expected to readers or interested people to preserve culture for generations, especially cultural aspect. Researcherss who are going to conduct further research and should understand the structural elements of Dayak Jangkang Tanjung folklore collection in Dusun Kompor Baru Desa Engkode Kecamatan Mukok Sanggau Regency.

Keyword: structural analysis, intrinsic, moral value, folklore

\section{PENDAHULUAN}

Indonesia merupakan wilayah yang memiliki beribu-ribu pulau. Dari beribu-ribu pulau menjadikan Indonesia mempunyai suku, bahasa daerah, adat istiadat, kebudayaan dan keragaman yang lainnya berbeda-beda. Dengan bermacam-macam kebudayaan menjadikan terkenal akan kebudayaan, seperti sastra lisan dan sastra tulisan. Sastra adalah salah satu budaya yang dimiliki oleh masyarakat, dimana masyarakat bermukim. Cerita rakyat merupakan salah satu sastra lisan yang muncul di masyarakat. Sastra lisan adalah cerita yang dituturkan secara langsung, sedangkan sastra tulis adalah cerita yang ditulis atau dibekukan ke bentuk tulisan.

Rampan (2014: 1) menyatakan "cerita rakyat merupakan cerita yang hidup di dalam lingkungan kolektif tertentu. Diangkat dari istilah bahasa Inggris folktale. Dalam kancah keilmuan, cerita rakyat dikenal dalam sebutan Inggrisnya sebagai folklore yang merujuk bahwa cerita rakyat merupakan milik suatu masyarakat tertentu yang berbeda dari masyarakat lainnya”. Jadi, begitu juga dengan sastra yang akan di teliti oleh peneliti di Dusun Kompor Baru yang terletak di Desa Engkode Kecamatan Mukok Kabupaten Sanggau merupakan suatu sastra milik masyarakat tersebut. Cerita rakyat tersebut merupakan cerita yang hidup di tengahtengah masyarakat yang diceritakan dari mulut ke mulut, dari generasi ke generasi lainnya. Cerita rakyat juga, biasa menceritakan kejadian yang sudah pernah terjadi di masa lalu.

Wellek dan Warren (dalam Endraswara, 2013: 9) menyatakan "pendekatan instrinsik adalah penelitian sastra yang bersumber pada teks sastra itu sendiri secara otonom. Sedangkan pendekatan ekstrinsik adalah penelitian unsur-unsur luar karya sastra yakni pengkajian konteks karya sastra di luar teks." Jadi, sebuah karya sastra terdapat dua pendekatan, yaitu pendekatan intrinsik dan ekstrinsik. Penelitian yang dilakukan oleh peneliti adalah menganalisis struktural, yaitu unsur intrinsik yang ada di dalam sebuah kumpulan cerita rakyat dan kemudian unsur ekstrinsik yang ada di dalam sebuah kumpulan cerita rakyat.

Ada beberapa cerita rakyat yang sampai saat ini, cerita tersebut masih dipercayai oleh masyarakat di Dayak Jangkang Tanjung Dusun Kompor Baru Desa Engkode Kecamatan Mukok Kabupaten Sanggau. Peneliti mendapatkan data penelitian dari seorang informan, bernama Dandan berusia 65 tahun, yang merupakan penduduk asli di Dayak Jangkang Tanjung 
Vol. 5, No. 1, April 2020

e-ISSN: 2540-7996

http://jurnal.stkippersada.ac.id/jurnal/index.php/KAN/index

Desa Engkode Kecamatan Mukok Kabupaten Sanggau selain menjadi seorang petani, beliau juga menjabat sebagai Ketua Adat. Kemudian informan kedua bernama Martina Minon, berusia 63 tahun beliau berkerja sebagai seorang petani. Demi menjaga sastra tersebut agar tidak punah, maka peneliti ingin melestarikannya.

Kumpulan cerita merupakan beberapa cerita rakyat yang lebih dari dua buah cerita yang akan diteliti oleh peneliti. Adapun cerita rakyat yang akan diteliti seperti cerita rakyat Anak Ngelaban, Pelangi, Dopo dan Doro, Hantu Gergasi, kemudian cerita rakyat yang terakhir Kurakura dan Kijang yang merupakan cerita berasal dari suku Dayak Jangkang Tanjung di Dusun Kompor Baru Desa Engkode Kecamatan Mukok Kabupaten Sanggau. Cerita rakyat Anak ngelaban menceritakan sebuah keluarga kemudian merebutkan kekuasaan. Kemudian cerita Pelangi menceritakan istri yang memaksa keadaan suaminya sedangkan, cerita Dopo dan Doro menceritakan kisah perjalanan kehidupan kakak beradik yang berawal tidak disukai oleh masyarakat karena masyarakat merasa iri dengan kehidupan mereka berdua yang serba berkecukupan.

Cerita Kakek Gergasi menceritakan kisah kehidupan keluarga yang berujung suaminya menjadi hantu bukit dan datang pada musim buah durian, kisah ini sampai saat ini masih dipercayai oleh masyarakat di Dayak Jangkang Tanjung Dusun Kompor Baru Desa Engkode Kecamatan Mukok Kabupaten Sanggau dan cerita yang terakhir adalah cerita rakyat kura-kura dan kijang, yang menceritakan kehidupan kura-kura yang berawal merebutkan lahan tanah dengan kijang. Mereka berdua bersepakat untuk bikin ladang kemudian, mereka berdua membakar ladang dengan setiap siapa yang duluan membakar ladang diam di tengah ladang yang sedang dibakar. Pada akhiranya, kura-kura yang menang sedangkan kijang mati di tengah ladang. Selanjutnya kisah hidup kura-kura tidak hanya sampai disitu saja, namun kisahnya masih berlanjut.

Hal ini yang membuat peneliti merasa tertarik ingin melestarikan sekaligus memperkenalkan kumpulan cerita rakyat yang ada pada Dayak Jangkang Tanjung Dusun Kompor Baru Desa Engkode Kecamatan Mukok Kabupaten Sanggau. Peneliti memilih judul ini, karena selain melestarikan kemudian memperkenalkan sastra lisan dan peneliti ingin menganalisis unsur struktural yaitu unsur intrinsik seperti tema, alur, latar, penokohan atau perwatakan, sudut pandangan, gaya bahasa, amanat dan nilai moral lebih mendalam dikumpulan cerita rakyat Dusun Kompor Baru Desa Engkode Kecamatan Mukok Kabupaten Sanggau karena belum diteliti oleh siapapun dan pentingnya menganalisis struktural, nilai 
Vol. 5, No. 1, April 2020

e-ISSN: 2540-7996

http://jurnal.stkippersada.ac.id/jurnal/index.php/KAN/index

moral agar mengetahui, memahami apa unsur pembangun dan nilai moral yang dapat dijadikan pelajaran dan diterapkan dalam kehidupan sehari-hari.

Di dalam cerita adanya unsur intrinsik dan nilai moral, untuk mengetahui unsur-unsur intrinsik kemudian nilai moral maka fokus penelitian yang di lakukan oleh peneliti adalah pada struktural karya sastra unsur intrinsik yaitu tema, alur, latar, penokohan atau perwatakan, sudut pandang, gaya bahasa, amanat dan unsur ekstrinsik merupakan unsur pembangun sastra dari luar. Peneliti membatasi analisis unsur ektrinsik pada unsur moral di dalam suatu karya sastra. Alasan peneliti memilih nilai moral karena cerita yang dianalisis kuat akan pesan moral yang masih relevan untuk masa sekarang.

Menurut Siswantoro (2010: 13) "struktur berarti bentuk keseluruhan yang kompleks (complex whole). Setiap objek, atau peristiwa adalah pasti sebuah struktur, yang terdiri dari berbagai unsur, yang setiap unsurnya tersebut menjalin hubungan”. Semi (dalam Suaka, 2014: 4) menyatakan "pendekatan struktural, yang paling utama dana pertama dilakukan adalah menguasai pengertian-pengertian dasar semua komponen yang membangun struktur. Dalam hal aspek instrinsiknya, karena yang membangun jadi titik fokus analisis, justru kepada komponen yang membangun karya sastra". Menurut Nurgiyantoro (2012: 36) bahwa struktur dalam sebuah karya sastra juga menyaran pada pengertian hubungan antara unsur (intrinsik) yang memiliki sifat timbal-balik, saling menentukan, dan saling mempengaruhi satu dengan yang lain. Kemudian akan secara bersamaan membentuk satu kesatuan yang utuh.

Cerita merupakan sebuah kisah yang menjelaskan tentang suatu kejadian yang sudah pernah terjadi di masa lampau atau di masa lalu. Sedangkan rakyat merupakan sekelompok orang yang menepati suatu tempat atau bermukim di suatu tempat. Jadi, dapat disimpulkan cerita rakyat merupakan sebuah kisah yang menjelaskan baik itu tentang suatu kejadian atau peristiwa yang pernah terjadi di sebuah tempat pemukiman. Pratama (2016: 3) "cerita rakyat adalah golongan cerita yang hidup dan berkembang secara turun menurun dari generasi ke generasi berikutnya. Disebut cerita rakyat karena cerita ini hidup di kalangan rakyat dan hampir semua lapisan masyarakat mengenal cerita itu. Cerita rakyat milik masyarakat bukan milik seseorang”. Rampan (2014: 1) menyatakan “cerita rakyat merupakan cerita yang hidup di dalam lingkungan kolektif tertentu. Diangkat dari istilah bahasa Inggris folktale. Dalam kancah keilmuan, cerita rakyat dikenal dalam sebutan Inggrisnya sebagai folklore yang merujuk bahwa cerita rakyat merupakan milik suatu masyarakat tertentu yang berbeda dari masyarakat lainnya". 
Vol. 5, No. 1, April 2020

e-ISSN: 2540-7996

http://jurnal.stkippersada.ac.id/jurnal/index.php/KAN/index

Struktural dalam cerita rakyat merupakan unsur pembangun dari dalam (Intrinsik) yaitu adanya tema, alur, latar, penokohan atau perwatakan, sudut pandang, gaya bahasa dan amanat. Menurut Sumardjo dan Saini (dalam Helena dan Rustiati, 2015: 105-106) menyatakan "tema adalah ide sebuah cerita. Menurut Semi (dalam Helena dan Rustiati, 2015: 103) "alur adalah struktur rangkaian kejadian dalam cerita yang disusun sebagai sebuah interrelasi fungsional yang sekaligus menandai urutan bagian-bagian dalam keseluruhan fiksi”. Menurut Wiyatmi (dalam Helena dan Rustiati, 2015: 104) sebagai berikut: Latar dibedakan menjadi tiga macam, yaitu latar tempat, waktu, dan sosial. Latar tempat berkaitan dengan masalah geografis. Di lokasi mana peristiwa terjadi, di desa apa, kota apa, dan sebagainya. Latar waktu berkaitan dengan masalah waktu, hari, jam, maupun historis. Latar sosial berkaitan dengan kehidupan masyarakat. Nurgiyantoro (2012: 165) menyatakan istilah tokoh merupakan menunjukan pada orang atau pelaku di dalam cerita, yang biasanya tentang siapa dan apa berapa orang yang berperan di dalam cerita sedangkan watak, perwatakan dan karakter merupakan menujukkan pada sikap, sifat tokoh di dalam cerita atau lebih kepada kualitas dari tokoh dalam cerita. Nurgiyantoro (2012: 248) mengatakan sudut pandang pada akikatnya merupakan sebuah cara, teknik atau pemeriksaan sangat teliti secara sengaja dipilih dan digunakan oleh pengarang untuk mengungkapkan sebuah gagasan dan ceritanya. Segala sesuatu yang dikemukakan dalam karya fiksa, memang, milik pengarang, pandangan hidup dan menjelaskan kehidupan. Namun, semuanya itu dalam karya fiksi disalurkan lewat sudut pandang tokoh, melalui penglihatan tokoh dalam tokoh. Nurgiyantoro (2012: 272) menyatakan "bahasa dalam sastra pun mengemban fungsi utamanya: fungsi komunikatif'. Sudjiman (dalam Helena dan Rustiati, 2015: 107) menyatakan "amanat merupakan gagasan yang mendasari karya sastra, pesan yang ingin disampaikan pengarang kepada pembaca atau pendengar".

Struktural dalam cerita rakyat merupakan unsur pembangun dari luar (Ekstrinsik). Nurgiyantoro (2012: 23) mengatakan "unsur ekstrinsik (extrinsic) adalah unsur-unsur yang berada di luar karya sastra itu, tetapi secara tidak langsung memperngaruhi bangunan atau sistem organisme karya sastra. Atau, secara lebih khusus ia dapat dikatakan sebagai unsurunsur yang mempengaruhi bangun cerita sebuah karya sastra, namun sendiri tidak ikut menjadi bagian di dalamnya”. Kemudian pada unsur ekstrinsik, peneliti hanya menganalisis nilai moral yang terdapat pada kumpulkan cerita rakyat pada Dusun Kompor Baru Desa Engkode Kecamatan Mukok Kabupaten Sanggau. Firwan (2017: 51) menyatakan "nilai berasal dari bahasa latin vale're yang artinya berguna, mampu akan, berdaya, berlaku, sehingga nilai diartikan sebagai sesuatu yang dipandang baik, bermanfaat dan paling benar menurut 
Vol. 5, No. 1, April 2020

e-ISSN: 2540-7996

http://jurnal.stkippersada.ac.id/jurnal/index.php/KAN/index

keyakinan seseorang atau sekelompok orang. Nilai adalah kualitas suatu hal yang menjadikan hal itu disukai, diinginkan, dikejar, dihargai, berguna dan dapat membuat orang yang menghayatinya menjadi bermartabat”. Menurut Suhada (2017: 77) “istilah Moral berasal dari kata latin "Mos, Moris, dan Mores", yang berarti adat istiadat, kebiasaan, peraturan/nilai-nilai atau tata cara dalam kehidupan". Hasanah (2017: 121) menyatakan "ada berbagai jenis dan wujud ajaran yang bersifat mendidik, yaitu mengenai baik berupa nilai moral religius seperti nilai moral tentang hubungan manusia dengan Tuhannya, kemudian nilai moral sosial kemasyarakatan seperti nilai moral tentang hubungan manusia dengan sesama manusia, termasuk dengan dirinya sendiri, ataupun nilai moral pemeliharaan dan pelestarian alam berkaitan nilai moral tentang hubungan manusia dengan lingkungan alamnya".

\section{METODE PENELITIAN}

Metode penelitian yang peneliti gunakan merupakan metode kualitatif yang berbentuk deskriptif. Menurut Amir (2013: 146) menyatakan "metode secara sederhana adalah cara ilmiah yang dilakukan untuk mengkaji sebuah objek: menghimpun data, menglasifikasi, menganalis atau menjelaskan". Gunawan (2016: 80) "metode kualitatif berusaha memahami dan menafsirkan makna suatu peristiwa interaksi tingkah laku manusia terkadang perspektif berdasarkan penelitian sendiri. Penelitian yang menggunakan penelitian kualitatif bertujuan untuk memahami objek yang diteliti secara mendalam". Penelitian deskriptif merupakan penelitian yang menggambarkan keadaan kejadian sesuai dengan apa yang di lihat karena penelitian ini bertujuan untuk menggambarkan struktural dan nilai moral dari kumpulan cerita rakyat di Dayak Jangkang Tanjung Dusun Kompor Baru Desa Engkode Kecamatan Mukok Kabupaten Sanggau.

Menurut Siswantoro (2010: 72) menyatakan "sumber data terkait dengan subjek penelitian dari mana data diperoleh. Subjek penelitian sastra adalah teks-teks novel, novela, cerita pendek, drama dan puisi”. subjek penelitian adalah masyarakat dari Suku Dayak Jangkang Tanjung Desa Engkode Kecamatan Mukok Kabupaten Sanggau dan informan dalam penelitian ini, mempunyai beberapa kriteria sebagai berikut:

a) Masyarakat asli dari Dayak Jangkang Tanjung Desa Engkode Kecamatan Mukok Kabupaten Sanggau.

b) Mengetahui cerita rakyat yang ada pada Dayak Jangkang Tanjung Desa Engkode Kecamatan Mukok Kabupaten Sanggau. 
Vol. 5, No. 1, April 2020

e-ISSN: 2540-7996

http://jurnal.stkippersada.ac.id/jurnal/index.php/KAN/index

Sukardi (2017: 205) "objek penelitian sejarah adalah peristiwa atau kehidupan masyarakat pada masa lampau maka yang menjadi sumber informasi harus mempunyai karakteristik yang berbeda dengan metode penelitian lainnya". Objek penelitian ini adalah kumpulan cerita rakyat dan struktural cerita rakyat di Dayak Jangkang Tanjung Dusun Kompor Baru Desa Engkode Kecamatan Mukok Kabupaten Sanggau dan penelitian ini dilaksanakan di Dusun Kompor Baru Desa Engkode Kecamatan Mukok Kabupaten Sanggau merupakan suku Dayak Jangkang Tanjung. Masyarakat Dusun Kompor Desa Engkode Kecamatan Mukok Kabupaten Sanggau memiliki pekerjaan sebagai petani karet, petani sawah. Dusun Kompor Baru Desa Engkode Kecamatan Mukok Kabupaten Sanggau memiliki luas wilayah 79,5 Km persegi dari sembilan dusun dan agama masyarakat banyak beragama khatolik. Masyarakat Dusun Kompor Baru Desa Engkode memiliki adat istiadat, kebudayaan, serta sastra yang masih ada dan diterapkan. Salah satunya adalah sastra lisan yang dilakukan orangtua zaman dahulu kepada anaknya sebelum tidur. Sastra lisan dilakukan sebagai cerita pengantar tidur anak. Sastra merupakan salah satu kebudayaan yang di miliki oleh masyarakat dimana mereka bermukim dan agar sastra tersebut tidak punah perlunya pelestarian. Untuk memperoleh data guna menjawab rumusan masalah maka teknik pengumpulan data yang tepat. Sugiyono (2014: 224) menyatakan "teknik pengumpulan data merupakan langkah yang paling strategis dalam penelitian, karena tujuan utama dari penelitian adalah mendapatkan data. Tanpa mengetahui teknik pengumpulan data, maka penelitian tidak akan mendapatkan data yang memenuhi standar data yang ditetapkan". Teknik pengumpulan data peneliti menggunakan teknik observasi dan teknik perekaman. Selain itu, teknik pengambilan data yang digunakan peneliti adalah teknik purposive sampling. teknik observasi merupakan observasi awal yang dilakukan peneliti untuk mendapatkan informan yang ada di Dayak Jangkang Tanjung Desa Engkode Kecamatan Mukok Kabupaten Sanggau, teknik perekaman merupakan teknik yang dilakukan oleh peneliti untuk mendapatkan sebuah data yang berupa kumpulan cerita rakyat yang ada di Dayak Jangkang Tanjung Desa Engkode Kecamatan Mukok Kabupaten Sanggau dari informan. Siswantoro (2010: 73) menyatakan "instrumen berarti alat yang dipergunakan untuk mengumpulkan data". Jadi, dapat ditarik kesimpulan bahwa instrumen merupakan alat yang digunakan oleh peneliti ketika melakukan penelitian dan peneliti menggunakan lembar observasi yaitu, handpone android, kamera handpone. 
Vol. 5, No. 1, April 2020

e-ISSN: 2540-7996

http://jurnal.stkippersada.ac.id/jurnal/index.php/KAN/index

PEMBAHASAN

Berikut ini adalah analisis data tentang analisis struktural kumpulan cerita rakyat Dayak Jangkang Tanjung Dusun Kompor Baru Desa Engkode Kecamatan Mukok Kabupaten Sanggau, yang dianalisis berdasarkan dua rumusan masalah yaitu, rumusan masalah yang pertama adalah bagaimanakah unsur intrinsik dalam kumpulan cerita rakyat Dayak Jangkang Tanjung Dusun Kompor Baru Desa Engkode Kecamatan Mukok Kabupaten Sanggau?, dan bagaimanakah nilai moral dalam kumpulan cerita rakyat Dayak Jangkang Tanjung Dusun Kompor Baru Desa Engkode Kecamatan Mukok Kabupaten Sanggau?.

1. Unsur Intrinsik Kumpulan Cerita Rakyat Dayak Jangkang Tanjung Dusun Kompor Baru Desa Engkode Kecamatan Mukok Kabupaten Sanggau adalah sebagai berikut.

a. Tema

Tema merupakan gagasan utama atau ide pokok pikiran yang terdapat didalam suatu karya sastra. Tema dapat diangkat berdasarkan isi cerita yang pertama berjudul "Anak Ngelaban” ini adalah keangkuhan. Berikut ini kutipan yang menunjukkan tema:

(57)namun adik bungsu yang namanya Ngelaban menunjukan bahwa dia kuat.

(66)"Sekarang ini Simpai Gerunon aku mencari kamu karena mendengar dari kata orang, kamu menjadi orang panglima. Aku ini yang seorang panglima maka aku melawan dan kita dua berperang" kata Ngelaban.

b. Alur

Alur merupakan unsur pembangun rangkaian sebuah kejadian cerita yang di dalamnya disusun oleh hubungan yang saling mengpengaruhi atau hubungan yang saling berkaitan dengan bagian-bagian dari dalam keseluruhan cerita dan plot merupakan sebuah urutan kejadian yang ada di dalam cerita, plot terjadi karena adanya sebab akibat yang kemudian menimbulkan kejadian baru. Alur dari cerita pertama berjudul "Anak Ngelaban" ini yaitu menggunakan alur maju. Alur maju dapat dilihat dari awal dan akhir cerita. Pada awal cerita, Ngelaban tumbuh besar, perkasa, rajin kerja dan memiliki tenaga yang kuat, dan terakhirnya dia membuat pedang untuk mengalahkan Simpai Gerunon. Berikut ini kutipan cerita "Anak Ngelaban" yang menunjukkan alur maju:

(54)"Kemudian seiring waktu berlalu dia pun tumbuh besar, perkasa, rajin kerja, dan tenaga semakin kuat lalu mereka bersaudara

(52) pura-pura bermain lalu bertaruh, main permainan yang lainnya karena ingin main berperang ramai-ramai, para saudaranya seperti Dhaket, Layet dan saudara yang lainya tidak mampu melawan adik bungsu mereka. 
Vol. 5, No. 1, April 2020

e-ISSN: 2540-7996

http://jurnal.stkippersada.ac.id/jurnal/index.php/KAN/index

c. Latar

Latar dapat dibagi menjadi tiga yaitu latar tempat, latar waktu dan latar sosial dan ketiga unsur tersebut saling berkaitan hubungannya meski berbeda fungsi. Latar cerita yang pertama berjudul "Anak Ngelaba” ini antara lain latar waktu yaitu pada zaman dahulu. Berikut ini adalah kutipan yang menunjukkan latar:

1) Latar waktu

Latar waktu yaitu yang berhubungan dengan kapan kejadian tersebut terjadi misalnya, pagi hari, esok dan lain sebaginya. Berikut ini latar waktu dalam cerita:

a) Pada zaman dahulu

(12) Kata Dona ngelaban "Dia melahirkan, dia tinggal di tanah yang tidak jelas arahnya.

Berdasarkan kutipan (12) di atas bahwa latar waktu yaitu pada zaman dahulu menunjukan pada waktu di masa lalu dan pernah terjadi.

2) Latar tempat

Latar tempat yaitu merujuk atau mengarah pada sebuah tempat kejadian dalam cerita, misalnya pemukiman penduduk, hutan, sungai dan lain sebagainya. Latar tempat dalam cerita pertama berjudul "Anak Ngelaba” yaitu rumah, hutan, dan bukit. Berikut ini latar tempat:

a) Rumah

(27) Dia pun pulang ke rumah

3) Latar sosial

.Latar sosial yaitu yang mencangkup dari keseluruhan hubungan dengan kehidupan masyarakat, misalnya kepercayaan agama, adat istiadat. latar sosial yaitu berkaitan dengan kebiasan kehidupan. Berikut ini kutipan latar sosial dalam cerita pertama berjudul "Anak Ngelaban":

(56)Kata Panyi Pencolai "Kamu jangan melawan aku dek, aku yang membantu kamu dulu waktu kamu mau lahiran kalau tidak aku bantu kamu tidak mungkin kamu ada sekarang. Kok kamu sekarang mau melawan aku?".

(57)adik bungsu yang namanya Ngelaban menunjukan bahwa dia kuat.

d. Penokohan dan Perwatakan

Penokohan merupakan orang-orang yang terdapat dalam cerita, sedangkan perwatakan merupakan tingkah laku yang dimiliki dari orang yang dalam cerita. Adapun penokohan dalam cerita yang pertama berjudul “Anak Ngelaban atau Dona Ngelaban” yaitu Mama 
Vol. 5, No. 1, April 2020

e-ISSN: 2540-7996

http://jurnal.stkippersada.ac.id/jurnal/index.php/KAN/index

Ngelaban, Panyi Pencolai, Nenek Bayan, Ngelaban, Bapak Ngelaban dan Simpai

Gerunon. Berikut ini kutipan yang menunjukkan penokohan dan perwatakan dalam cerita anak Ngelaban:

1) Mama Ngelaban

(38)"Jangan bang (abang atau bang merupakan sebutan untuk anak laki-laki) mama kasihan melihat kamu karena kamu masih bayi, tali pusat kamu masih ada habis itu kamu mau berjalan. Kuat benar kamu bang? tidak mampu saudaramu lawan kamu" kata mamanya.

Berdasarkan kutipan (38) di atas menunjukkan bahwa watak dari Mama Ngelaban terlihat sangat penyayang dan peduli kepada anaknya.

e. Sudut Pandang

Sudut pandang merupakan suatu cara yang digunakan pengarang atau pencerita untuk menyampaikan makna atau maksud baik pesan moral dari cerita yang dibaca oleh pembaca. Sudut pandang yang digunakan oleh pencerita dalam cerita pertama berjudul "Anak Ngelaban atau Dona Ngellaban" adalah sudut pandang campuran dan dapat dilihat dari awal sampai akhir menceritakan tokoh menggunakan kata "aku, dia, kamu, kami, mereka, nama tokoh". Berikut kutipan yang menunjukan kata "aku, dia, kamu, kami, mereka, nama tokoh":

(21) Kata Panyi Pencolai "Oh nenek Bayan Bunga aku ke sini mau ketemu dengan nenek, mamaku mau melahirkan".

(66)"Sekarang ini Simpai Gerunon aku mencari kamu karena mendengar dari kata orang kamu menjadi orang panglima, aku ini yang seorang panglima maka aku melawan dan kita dua berperang" kata Ngelaban.

f. Gaya Bahasa

Gaya bahasa merupakan bahasa yang digunakan pencerita saat melakukan bercerita atau berkomunikasi. Gaya bahasa yang digunakan oleh pencerita dalam cerita pertama berjudul “Anak Ngelaban atau Dona Ngelaban” adalah majas metafora. Majas metafora merupakan gaya bahasa perbandingan dengan memperbandingkan suatu benda dengan benda yang lain karena mempunyai sifat yang sama atau hampir sama. Berikut kutipan yang menunjukan gaya bahasa majas metafora:

(67)Jadilah pedangnya untuk lawan Simpai Gerunon, berperanglah mereka berdua bukit menjadi darat, darat menjadi bukit lalu akhirnya lama-lama berperang di bukit (68)tidak ada arah siapa yang kalah dan mengalah karena melihat tidak ada yang kalah. 
Vol. 5, No. 1, April 2020

e-ISSN: 2540-7996

http://jurnal.stkippersada.ac.id/jurnal/index.php/KAN/index

g. Amanat

Amanat merupakan sebuah ide mendasari sebuah karya sastra, kemudian adanya sebuah pesan yang ingin disampaikan pengarang melalui sebuah karya tersebut. Amanat yang dapat disimpulkan dari cerita pertama berjudul "Anak Ngelaban atau Dona Ngelaban" ini adalah sebagai anak jangan melawan perkataan orang tua atau orang yang lebih tua. Berikut kutipan yang menunjukkan jangan melawan perkatan orangtua:

(58) "Jangan melawan kakakmu, jangan katanya jangan" kata Panyi Pancolai menasehatin adik bungsunya.

(59) Lalu Ngelaban merasa mulai sombong karena merasa dia kuat,

Berdasarkan kutipan (58), (59) dapat dilihat amanatnya adalah jadilah seorang anak yang patuh terhadap perintah orangtua, dan tidak keras kepala.

2. Nilai Moral Kumpulan Cerita Rakyat Dayak Jangkang Tanjung Dusun Kompor Baru Desa Engkode Kecamatan Mukok Kabupaten Sanggau.

a. Nilai moral

Suatu nilai yang baik, buruk dari setiap perilaku-perilaku manusia dalam bermasyarakat. Nilai moral dapat dijadikan pelajaran di kehidupan sekarang. Nilai moral memiliki beberapa hubungan antara lain: manusia dengan Tuhan, bagaimana sikap, tingkah laku manusia ketika berinteraksi dengan Tuhan. Kemudian yang kedua, hubungan antara manusia sesama manusia yang berkaitan dengan tingkah laku terhadap lawan interaksinya ketika bersosial atau bermasyarakat. Terakhir adalah hubungan antara manusia dengan alam dimana tempat mereka tinggal, berkaitan bagaimana sikap, tingkah laku manusia dengan alam sekitarnya.

Nilai moral dari cerita pertama berjudul "Anak Ngelaban” ini adalah berkaitan dengan tingkah laku terhadap lawan komunikasi ketika bersosial atau bermasyarakat seperti di dalam keluarga, dan dengan masyarkat yang lainnya. Nilai moral dalam cerita ini termasuk kurang baik karena di dalam interaksi keluarga ada ketidakharmonisan. Berikut ini kutipan yang menunjukan interaksi yang kurang baik dengan keluarga maupun masyarakat lain:

1) Komunikasi antara orangtua dengan anaknya dan anak sesama anak.

(15)aku mau melahirkan mau suruh adik kamu atau kamu Panyi". 
Vol. 5, No. 1, April 2020

e-ISSN: 2540-7996

http://jurnal.stkippersada.ac.id/jurnal/index.php/KAN/index

(16) Kata Panyi "Kami banyak bersaudara ada enam jika salah satunya mau disuruh".

2) Hubungan antara manusia sesama manusia

(21)Kata Panyi Pencolai "Oh nenek Bayan Bunga aku ke sini mau ketemu dengan nenek, mamaku mau melahirkan".

(22)Jawab nenek Bayan Bunga "Aduh bagaimana mama kamu mau melahirkan?".

\section{PEMBAHASAN}

Setelah melalui proses analisis data maka, didapatkan hasil analisis yang menjawab kedua rumusan masalah pertanyaan penelitian yang pertama yaitu bagaimanakah unsur intrinsik dalam kumpulan cerita rakyat Dayak Jangkang Tanjung Dusun Kompor Baru Desa Engkode Kecamatan Mukok Kabupaten Sanggau?. Pertanyaan kedua yaitu, bagaimanakah nilai moral dalam kumpulan cerita rakyat Dayak Jangkang Tanjung Dusun Kompor Baru Desa Engkode Kecamatan Mukok Kabupaten Sanggau?.

1. Unsur intrinsik dalam kumpulan cerita rakyat Dayak Jangkang Tanjung Dusun Kompor Baru Desa Engkode Kecamatan Mukok Kabupaten Sanggau.

Unsur intrinsik yang terdapat di dalam cerita pertama berjudul Anak Ngelaban memiliki tema yaitu keangkuhan. Alur yang terdapat dalam cerita pertama berjudul Anak Ngelaban yaitu alur maju. Latar yang terdapat dalam cerita pertama berjudul Anak Ngelaban antara lain latar waktu yaitu pada zaman dahulu. Latar tempat yaitu rumah, hutan, dan bukit. Latar sosial yaitu berkaitan dengan kebiasan kehidupan. Penokohan dan Perwatakan yang terdapat dalam cerita pertama berjudul Anak Ngelaban yaitu Mama Ngelaban memiliki watak sangat penyayang dan peduli kepada anaknya, Panyi Pencolai memiliki watak anak yang patuh terhadap orangtua, suka mengalah dan penyayang kepada adiknya, Nenek Bayan Bunga memiliki watak baik dan suka menolong, Ngelaban memiliki watak yang keras kepala, sombong, nekat, licik, namun suak menolong orangtua, rakin berkerja, dan kuat. Bapak Ngelaban memiliki watak pekerja keras, Simpai Gerunon memiliki watak mudah terjebak suasana dan pasrah. Sudut Pandang cerita pertama berjudul Anak Ngelaban yaitu sudut pandang campuran menggunakan kata “Aku, dia, kamu, kami, mereka, nama tokoh”. Gaya Bahasa yang terdapat cerita berjudul Anak Ngelaban yaitu majas metafora. Amanat yang terdapat di 
Vol. 5, No. 1, April 2020

e-ISSN: 2540-7996

http://jurnal.stkippersada.ac.id/jurnal/index.php/KAN/index

dalam cerita pertama berjudul Anak Ngelaban yaitu sebagai anak jangan melawan perkataan orangtua atau orang yang lebih tua.

2. Nilai Moral yang terdapat dalam kumpulan cerita rakyat Dayak Jangkang Tanjung Dusun Kompor Baru Desa Engkode Kecamatan Mukok Kabupaten Sanggau

Nilai moral dalam cerita yang pertama berjudul Anak Ngelaban yaitu berkaitan dengan tingkah laku terhadap lawan komunikasi ketika bersosial atau bermasyarakat seperti di dalam keluarga, dan masyarakat yang lainnya. Nilai moral dalam cerita ini termasuk kurang baik karena di dalam interaksi keluarga ada ketidakharmonisan.

\section{SIMPULAN}

Dari keseluruhan analisis sesuai dengan rumusan masalah yang ada terhadap kumpulan Cerita Rakyat yang peneliti lakukan di Dayak Jangkang Tanjung Dusun Kompor Baru Desa Engkode Kecamatan Mukok Kabupaten Sangggau dapat disimpulkan unsur intrinsik cerita Anak Ngelaban meliputi tema yaitu keangkuhan. Alur yang terdapat dalam cerita pertama berjudul Anak Ngelaban yaitu alur maju. Latar yang terdapat dalam cerita pertama berjudul Anak Ngelaban antara lain latar waktu yaitu pada zaman dahulu. Latar tempat yaitu rumah, hutan, dan bukit. Latar sosial yaitu berkaitan dengan kebiasan kehidupan. Penokohan dan Perwatakan yang terdapat dalam cerita pertama berjudul Anak Ngelaban yaitu Mama Ngelaban memiliki watak sangat penyayang dan peduli kepada anaknya, Panyi Pencolai memiliki watak anak yang patuh terhadap orangtua, suka mengalah dan penyayang kepada adiknya, Nenek Bayan Bunga memiliki watak baik dan suka menolong, Ngelaban memiliki watak yang keras kepala, sombong, nekat, licik, namun suak menolong orangtua, rakin berkerja, dan kuat. Bapak Ngelaban memiliki watak pekerja keras, Simpai Gerunon memiliki watak mudah terjebak suasana dan pasrah. Sudut Pandang cerita pertama berjudul Anak Ngelaban yaitu sudut pandang campuran menggunakan kata "Aku, dia, kamu, kami, mereka, nama tokoh". Gaya Bahasa yang terdapat cerita berjudul Anak Ngelaban yaitu majas metafora. Amanat yang terdapat di dalam cerita pertama berjudul Anak Ngelaban yaitu seabagai anak jangan melawan perkataan orangtua atau orang yang lebih tua. Nilai moral dalam cerita yang pertama berjudul Anak Ngelaban yaitu berkaitan dengan tingkah laku terhadap lawan komunikasi ketika bersosial atau bermasyarakat seperti di dalam keluarga, dan masyarakat yang lainnya. Nilai moral dalam cerita ini termasuk kurang baik karena di dalam interaksi keluarga ada ketidakharmonisan. 
Vol. 5, No. 1, April 2020

e-ISSN: 2540-7996

http://jurnal.stkippersada.ac.id/jurnal/index.php/KAN/index

\section{DAFTAR PUSTAKA}

Ana, Helena dan Rustiati. 2015. "Penokohan, Alur, Latar, Tema, Dan Amanat, Serta Nilai Moral Dalam Novel Surga Retak Karya Syahmedi Dean". Jurnal FKIP-Universitas Katolik Widya Mandala Mandiun. Volume 2 No. 1 Hal 103, Hal 105, Hal 107.

Amir, Adriyetti. 2013. Sastra Lisan Indonesia. Yogyakarta: Cv Andi Offset.

Endraswara, Suwardi. 2013. Metodologi Penelitian Sastra. Yogyakarta: CAPS (Center for Academic Publishing Service).

Firwan, Muhammad. 2017. "Nilai Moral Dalam Novel Sang Pencerah Karya Akmal Napey Basral". Jurnal Bahasa dan Sastra. Volume 2. No 2 Hal 51.

Gunawan, Imam. 2016. Metode Penelitian Kualitatif Teori \& Praktik. Jakarta: PT. Bumi Aksara.

Hasanah, Uswatun. 2017. "Nilai Moral Dalam Sāq Al-Bambū Karya Sa 'Ūd Al-San'Ūsī”. Jurnal Bahasa dan Sastra. Volume I No. 1 Hal 120-121.

Nurgiyantoro, Burhan. 2012. Teori Pengkajian Fiksi. Yogyakarta: Gadjah Mada University Press.

Pratama, Eram Putra. 2016. "Nilai Pendidikan Dalam Cerita Rakyat Tolaki Oheo dan Onggab". Jurnal Humanika. Volume 1 No. 16 Hal 3.

Rampan, Korrie Layun. 2014. Teknik Menulis Cerita Rakyat. Bandung: Penerbit Yrama Widya.

Suaka, I Nyoman. 2014. Analisis Sastra Teori Dan Aplikasi. Yogyakarta: Ombak.

Sugiyono. 2014. Metode Penelitian Kuantitatif, Kualitatif Dan R\&D. Bandung: Alfabeta.

Suhada, Idad. 2017. Perkembangan Peserta Didik. Bandung: PT. Remaja Rosdakarya.

Sukardi. 2017. Metodologi Penelitian Pendidikan. Jakarta: PT. Bumi Aksara.

Siswantoro. 2014. Metode Penelitian Sastra Analisis Struktur Puisi. Yogyakarta: Pustaka Pelajar. 


\section{Petunjuk Bagi (Calon) Penulis Jurnal KANSASI}

1. Artikel yang ditulis untuk Jurnal KANSASI adalah hasil telaah dan hasil penelitian dibidang pendidikan, bahasa, dan sastra Indonesia serta tidak pernah diterbitkan dimedia lain, baik cetak maupun elektronik.

2. Naskah diketik dengan huruf Times New Romans, ukuran 12, dengan spasi 1,5, menggunakan kertas A4, margin atas, kiri, kanan dan bawah $2.54 \mathrm{~cm}$, dengan maksimum 20 halaman, dan diserahkan secara online melalui laman (http://jurnal.stkippersada.ac.id/jurnal/index.php/KAN) pada bagian submission, dan terlebih dahulu penulis melakukan registrasi sebagai penulis (author). Pada saat diserahkan, file dalam format $p d f$.

3. Nama penulis artikel dicantumkan tanpa gelar akademik dan di tempatkan di bawah judul artikel. Nama penulis hendaknya dilengkapi dengan alamat lembaga tempat penelitian serta alamat korespondensi. Bila naskah ditulis oleh tim, maka penyunting hanya berhubungan dengan penulis utama.

4. Artikel ditulis dalam bahasa Indonesia dengan format esai, disertakan judul masingmasing bagian artikel. Judul artikel dicetak dengan huruf kapital dengan posisi tengah atas dengan ukuran huruf 14 serta ditebalkan.

5. Sistematika artikel hasil telaah adalah: judul, nama penulis (tanpa gelar), identitas lembaga, alamat e-mail, abstrak (maksimum 250 kata), kata kunci, pendahuluan; pembahasan, simpulan, dan daftar pustaka.

6. Sistematika artikel hasil penelitian adalah: judul, nama penulis (tanpa gelar), abstrak (maksimum 250 kata), pendahuluan, metode penelitian, pembahasan, simpulan, dan daftar pustaka.

7. Sumber rujukan minmal terbitan sepuluh tahun terkahir. Rujukan yang diutamakan adalah sumber-sumber primer berupa laporan penelitian, atau artikel penelitian terbitan jurnal ilmiah.

8. Perujukan, pengutipan, tabel, dan gambar menggunakan ketentuan yang ada pada template penulisan artikel ilmiah pada Jurnal KANSASI.

9. Naskah diketik sesuai dengan tata bahasa baku bahasa Indonesia.

10. Setiap naskah ditelaah oleh penyunting ahli (reviewer) yang ditunjuk oleh penyunting sesuai dengan bidang kepakaran. Penulis artikel diberi kesempatan untuk merivisi naskah berdasrkan rekomendasi dari penyunting. Pemuatan atau penolakan naskah akan diberitahukan secara online melalui e-mail.

11. Penyuntingan naskah pra-terbit dikerjakan oleh penyunting (editor). Naskah pra-terbit dapat batal diterbitkan apabila diketahui bermasalah.

12. Segala sesuatu yang menyangkut perizinan atau penggunaan software computer untuk pembuatan naskah atau hal lain yang terkait dengan pelanggaran hak cipta yang dilakukan oleh penulis, serta konsekuensi hukum yang mungkin timbul karenanya, sepenuhnya menjadi tanggungjawab penulis. 